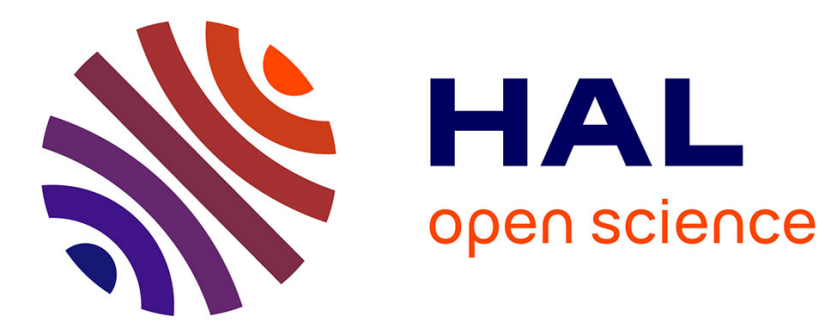

\title{
Medical Imaging and Modern Art: Encounters over a Virtual Body \\ Rémy Potier
}

\section{To cite this version:}

Rémy Potier. Medical Imaging and Modern Art: Encounters over a Virtual Body. Recherches en psychanalyse, 2011, Psychanalyse, corps et Société / Psychoanalysis, the Body and Society, 2 (12), pp.131 - 139. 10.3917/rep.012.0131 . hal-01516343

\section{HAL Id: hal-01516343 \\ https://hal.science/hal-01516343}

Submitted on 18 Jul 2017

HAL is a multi-disciplinary open access archive for the deposit and dissemination of scientific research documents, whether they are published or not. The documents may come from teaching and research institutions in France or abroad, or from public or private research centers.
L'archive ouverte pluridisciplinaire HAL, est destinée au dépôt et à la diffusion de documents scientifiques de niveau recherche, publiés ou non, émanant des établissements d'enseignement et de recherche français ou étrangers, des laboratoires publics ou privés. 


\title{
Recherches en Psychanalyse - Research in Psychoanalysis
}

12 |2011- Psychoanalysis, the Body and Society

Psychanalyse, corps et Société

\section{Special topic: "Psychoanalysis, the Body and Society"}

\section{Medical Imaging and Modern Art: Encounters over a Virtual Body}

Imagerie médicale et art contemporain, rencontres autour d'un corps virtuel

Rémy Potier

\begin{abstract}
:
Modern art offers us a singular and revealing perspective on the body and the way it is experienced today. Based on this interest in the body, the latter's virtualization has also become a source of artistic inspiration. To present this virtual body, artists sometimes use images produced by medical imaging technologies. The actualization of the virtual body poses a question for them. The images of the body produced by medicine are thus integrated into their artistic works. In an era of sophisticated technological equipment, this encounter between art and medicine raises the question of the position of these images in our culture and the way in which they illustrate our relationship to otherness and to death. Today, medical imaging provides one of the key illustrations of the body, seen at its most intimate. This technology is the inescapable medium through which we imagine our living body, a body that is subject to illness and doomed to death. It is therefore useful to look at contemporary art and what it tells us about the subject's encounter with medical imaging. The cultural discontent of today is closely related to our immersion in the (virtual) image, while the access to and use of these technologies is becoming increasingly widespread and extends far beyond the field of healthcare. Since the 20th century, art has been trying to show the aspects of the body that these techniques have allowed us to see, as they are gradually seeping into our culture one after another, and ultimately modify our relationship to the body and its representation. Xrays, close-ups, macrophotography-each of these have been enlisted in the service of art. This detour through art can teach us a great deal, helping us see the extent to which looking at these images confounds and challenges the very idea of representation.
\end{abstract}

\section{Résumé :}

L'art contemporain offre un regard singulier et révélateur concernant le corps, tel qu'il est aujourd'hui vécu. À partir de cet intérêt porté au corps, la question de la virtualisation de celui-ci est également devenue source d'inspiration. Des artistes se saisissent ainsi d'images véhiculées par la médecine à travers l'imagerie pour mettre en scène ce corps virtuel. C'est cette actualisation du corps virtuel qui interpelle les artistes. Ils intègrent ces images du corps issues de la médecine dans leur dispositif artistique. Cette rencontre entre art et médecine à l'heure des appareillages technique engage la question de la place acquise par ces images dans notre culture, et la façon dont celles-ci illustrent ce que devient notre rapport à l'altérité puis à la mort. L'une des illustrations du corps, aujourd'hui, dans sa visibilité la plus intime, est portée par l'imagerie médicale. Cette technique est le média incontournable par lequel nous nous représentons notre corps de chair, sujet à la maladie et voué à la mort. Il convient de se laisser saisir par l'art contemporain à partir de ce qu'il donne à penser de la rencontre du sujet avec l'imagerie médicale. Le malaise dans la culture, est aujourd'hui étroitement lié à ces immersions dans l'image (virtuelle) dont 
l'accès et les pratiques sont de plus en plus répandues, au-delà même du domaine de la santé. C'est ainsi 
que l'art depuis le XXe siècle montre du corps ce que les techniques de visualisation ont permis de voir les unes après les autres, s'insinuant dans la culture, au point de modifier le rapport au corps et à ses images. Les rayons $X$, les photographies en gros plan, la macrophotographie vont être enrôlés au service de l'art. Ce détour par l'art est très instructif, il permet de montrer combien le regard porté sur l'image médicale déroute et met à l'épreuve l'idée même de représentation.

Keywords : psychoanalysis, medical imaging, contemporary art, culture

Mots-clefs : psychanalyse, imagerie médicale, art contemporain, culture

\section{Plan:}

The Position of Medicine Today

Drawing Back the Veil on the Body, from Imaging to Art

Discussion

Illustrations

Discussion 2

Conclusion

Modern art offers us a singular and revealing perspective on the body and the way we conceive of it and experience it today. Based on this general interest in the body, the question of its virtualization has also become a source of artistic inspiration. Artists feel interpellated by the actualization of the virtual body in the sphere of healthcare; consequently, images provided by medicine are being used to stage this body in art and are being integrated into different artistic frameworks. This encounter between art and medicine - in an era of highly developed technical equipment - raises the question of the position these images have attained in our culture. They illustrate our relationship not only to our bodies, but also to otherness and death. In its highly intimate visibility, medical imaging constitutes one of today's key modes of representing the body, an inevitable medium through which we represent our body as living flesh, as a body subject to illness and destined to death. The cultural discontent of today is closely linked to this immersion in the (virtual) image, to which we gain increasingly better access and the practices of which are becoming more and more widespread.

Starting in the 20th century, art has been showing us the body through the increasingly sophisticated lens of imaging techniques. Artists have been asking about the way in which these technologies modify our relationship to the body and its images on the cultural level. Initially marginal artistic projects, such as the work of the French artist Orlan, have become routine practice in contemporary biotechnology, which aspires to rectify the organic form by intervening earlier and earlier, particularly at the level of genetics. This transformation of the body is driven by a search for its ideal and perfection. Regardless of their ultimate therapeutic, aesthetic and ludic results, these bodily transformations are part of the pursuit of an ideal body, a dream-like body that should become a reality through medical intervention. Modern art enables us to think of medical imaging in this context.

Works created by artists using medical imaging reveal the repressed aspects of the body of our time, its sexual dimension, which is eradicated in medical methodology itself.

I would firstly like to address the position that medicine holds in today's society and consider the role it plays in body representation. The reverse side of today's medicine is illustrated by the work of certain artists who foreground the question of the body. Foreign Body, an installation created by Mona Hatoum, allows us 
to illustrate and interrogate the effect of medical images and its intimate resonances. The interest in the medical image can be seen, in different ways, in the work of a number of other artists. My research aims to approach the question psychoanalytically, revealing the unconscious dimension of this close encounter with technology, and follow the process through which technology changes human beings and their self-representation.

\section{The Position of Medicine Today}

Today's medicine is technoscientific. I would like to show that this fact engenders a new representation of the body in the social field, including a new relationship of the subject to his own body. A normalizing process can be identified not only in the area of healthcare, but also on the anthropological level. Highlighting this dimension reveals the importance of an interdisciplinary perspective when studying medicine and more specifically medical imaging. The medical image of the body is an image of the internal body, a body that is constructed, one that is other and is continuously perceived as foreign. This body only comes into existence thanks to technologies of virtualization, and thanks to considerable computing power. The subject is confronted with an experience of immersion. The image represents the body, yet it is a body produced for medical purposes and only legible through medicine's own means. This is reflected in the social field on two levels. Firstly, at the level of the vocabulary related to the body, which becomes saturated with medical terms. Secondly, in what concerns the question of "transference," in the psychoanalytic sense of the term, as physicians encounter it today.

The language of medicine, its speech, is not failing to produce an effect on the construction of today's representation of the body. In present-day medical procedures, CT scanning, ultrasound and MRI have become as commonplace as traditional $\mathrm{x}$-ray scanning. "My doctor was not worried about my scan", "My ultrasound was strange"- these are just two examples of what patients say, examples which can illustrate the implication of the medical imaging technology in contemporary common parlance. This linguistic development should surprise us, in that it is the result of an unconscious formation based on personal experiences of different bodily encounters with these technologies, more often than not in a situation where the subject knows nothing of their real functioning and implications. In this type of speech, the body is seen through what exposes it - the organ is replaced by the investigative technology and lived experience is condensed into a high-tech magical formula. We can no longer speak about our body and its functioning without having recourse to medical vocabulary. The body is to us an ensemble of organs, which are the site of physiological and biochemical processes. Therefore, we designate and localize our illnesses according to medical geography and terminology, even if these do not exactly follow the official nomenclature.

Medical knowledge feeds into language and representation, yet to patients it remains largely impenetrable. Clearly, these borrowed words orient our body representation and experience, and the technical vocabulary we use allows us to turn our body into an external object we can keep, at least minimally, at a distance, thus warding off the concerns and worries it may be causing us. However, something remains outside representation and this remainder returns back to us. Psychoanalytic inquiry is interested precisely in this returning reminder. For medical practitioners, relating to a body as a purely external object has become a matter of course. The specificity of contemporary medical knowledge, in addition to the technical vocabulary we borrow from it, lies in the fact that the reconstructed body imposes itself on us as a supposed objectivity, despite being in reality a construction, from which we should - though it is not always possible - maintain some distance. Nonetheless, for the patient this body-object does not represent the whole truth of his illness. The demands of patients and the transference ${ }^{1}$ to the medical body must be understood in this 
context. However, today's religiosity is situated at the level of technological processes. Encouraged by the media, the amazed and fascinated society considers "medical progress" to be practically limitless. Television series such as ER, Grey's Anatomy or House have become a window onto the latest advances in medical technology; their scripts are co-written by medical practitioners and promote the use of medical terms. The viewer's incomprehension stimulates the heroic identification with the medical staff. If science is identified with progress, medicine is also thought to be able to produce miracles and this message constitutes its religiosity. Each new advance seems to efface the traces of the preceding one; however, medical progress is in fact achieved against a background haunted by the anxiety of death, which must constantly be warded off and silenced. Thus we see a number of contradictory visions clashing against each other. The physician's perspective on his own science is never identical to the patient's view of his illness and the words the latter learns from the media only accentuate the gap between these two perspectives, thus further complicating their encounter.

The movement from the real of the body into the virtuality of the parametric standards of images and figures, of this truly new reality, draws the consciousness of the body towards the outside. Techno-scientific medicine replaces subjectivity with medical science, which can, for better or worse, serve as the body's new identity. In the sense of a simple increase in possibilities, the new advances of psychopharmacology, electric interference or brain computing no longer make any difference between one's own body, neurotransmitters and external organs. Physicians tell us that a patient's condition may worsen simply because he is told about an existing risk of illness or because the doctors are unable to determine the cause ofhis malady; at other times, a condition can improve by virtue of the patient having received favorable results. We are no longer able to discern the truth about our bodies. On the collective level, this loss of individual trust in the signals of one's own body only becomes accentuated. The truth of the body is seen as residing in the hands of the medical practitioner. Medical progress is therefore resulting in the creation of a new and increasingly efficient real, while disregarding the fact that the human being too is being transformed.

This article will try to show what happens in the encounter with the imagery of the internal body, effects which the work of artists who use medical imaging techniques in their creative process brings into clearer focus.

Drawing Back the Veil on the Body, from Imaging to Art

In trying to understand the subject's encounter with medical imaging, modern art offers us an extremely useful perspective. I would like to begin by presenting the work of Mona Hatoum. We find that many contemporary artists have been inspired by medical technologies; the last decade of the $20^{\text {th }}$ century in particular experienced a new wave of body art. As an example of this work, I would like to discuss Hatoum's piece Foreign Body (1994).

Hatoum's work is a video installation showing endoscopic images of the interior of the artist's own body. My inquiry focuses on the fantasmatic logic it articulates as a correlate of the discourse and equipment produced by scientific technology. I argue that the artist depicts this logic in order to transmit her own gaze on the object. The artist's gaze unfolds in the device, reflecting something of the discontents of the modern perspective on the body.

As part of the body art tradition, Mona Hatoum's work has always foregrounded the body; camera surveillance has been another of her recurring themes. In Don't Smile, You're on Camera, a live performance which took place in 1980 , the public was filmed and its images mixed with others visual elements, for example juxtaposing a well-dressed spectator with a nude image or an $\mathrm{x}$-ray scan. When projected on 
screen, these images gave the impression of the camera's gaze slipping both under the person's clothes and under his skin. This staging of the problem of voyeurism gives the spectator a chance to experience the switch between voyeurism and exhibitionism. The artist therefore succeeds in producing a kind of metonymy of the effect experienced by the modern subject, who seems destined to become completely immersed in the world of images. However, this voyeurism is performed by the camera eye, which in Hatoum's 1994 piece Foreign Body in fact penetrates the body. This invasive gaze is simultaneously fascinating and terrifying, indeed violent. The work seems to imply both a fascination with the unknown parts of the body and a critique of the appropriative imaging technology, thus in fact restoring its anxiety-producing dimension.

Foreign Body consists of a type of cabin, which we can enter in order to see and feel the artwork. On the floor of the cabin there is a round screen, where we see the projection of enlarged footage of the surface and the interior of the artist's body. ${ }^{2}$ We can follow the endoscopic camera as it brushes against the artist's skin and penetrates through its orifices, such as the anus and the vagina, in order to film the body's insides. The movements of the camera are accompanied by the amplified noise of the artist's respiration and heartbeat: when the camera remains outside the body, we hear the sound of breathing; when it enters inside, we hear the sound of a heartbeat. The relatively small cabin and the necessity of standing directly on the screen give the spectator a feeling of being absorbed inside the artist's body. He is captured in a "strangely intimate circle" between the body's interior and exterior. Mona Hatoum participated in the production of this video by remaining awake and conscious during a medical exam. The work unveils before us the most intimate areas of her body, the access to which is in principle solely reserved to the medical gaze as an organ of control. This is the first meaning of the work's title, which designates the camera as the extension of the scientific gaze, as an external element penetrating the patient's body, appropriating it and reporting on it through deconstructed images. To the extent that the examined body, in spite of its familiarity, becomes itself foreign, unrecognizable to the individual to whom it belongs - leaving aside the fact that medical imagery can sometimes reveal an anomaly unsuspected by the subject, thus adding to the feeling of alienation towards one's own body. In addition, the expression Foreign Body also refers to the spectator's position within the framework of the installation. In deciding to enter the structure that houses the endoscopic video, the spectator becomes involved with an unknown body, which he is invited to explore through the larger-than-life images, amplifying the effect of being immersed in another territory, delimited by the circular architecture. Whether the spectator bypasses the image by walking alongside the inner walls of the structure surrounding the video, or whether he decides to cross the projection screen diagonally, he cannot avoid a confrontation with a body shown in its most biological aspects.

The type of structure designed by the artist to contain the endoscopic video has a determining effect on the reception of the work by the spectator: the relatively small form of the cylinder - accessible only through two narrow doors suggests a private space with limited access. This feeling is accentuated by the almost complete darkness of the surroundings (the video images are the only source of light in the installation). Then, once the spectator has entered the structure, the extremely intimate nature of the projected images inevitably puts him in the position of a voyeur. Moreover, Foreign Body also refers to the notion of surveillance and the correlation between the gaze and power, a notion largely developed by Foucault. Indeed, the encounter within this architectural space, between the artist's body and the spectator's gaze, functions as a spatial reconstruction of the power exercized by the medical institution through its scientific gaze, which is directed to the vulnerable body of the patient. 
Foreign Body is not one's own body; it is not my body but the body of an other. Yet the body shown on the screen is no longer completely familiar even to the artist herself. The intervention of a foreign entity in one's own body highlights the camera's role cameras inquisitor, used by Hatoum to signify the way in which medicine confronts us with an experience of intrusion par excellence.

\section{Discussion}

What can we say about this encounter with the foreignness of images? The screen of Foreign Body shatters the mirror of narcissism. Foreign Body profoundly disturbs the relation between one's own body and the foreign body; however, this does not mean that the latter replaces the former.

From a phenomenological perspective, Jenny Slatman $^{3}$ argues that the new images of the internal body provided by medical imaging (ultrasound, endoscopy, MRI, CT and PET), affect body image as the experienced bodily identity. She adds: "Because these new images fragmented and virtually unrecognizable - are not easily integrated into the specular image of our body, we must move beyond a theory of narcissism that would reduce body image to 'visual image'." ${ }^{4}$ Slatman therefore proposes a concept of the "affective image." However, it seems to me that rather than trying to use the images of the inner body to tame us, Hatoum's work shows us the anxiety of fragmentation such visual experience necessarily provokes.

What seems to be at stake here is one of the issues identified by Lacan's theory of the mirror stage. The infant recognizes his specular image but cannot yet perceive that there is a difference between this image and himself: the image is "misrecognized" (Lacan, 2006, 80). The child cannot yet recognize the otherness of the image; he confuses himself with the other. The structure constructed by Mona Hatoum translates this strange alternative by imposing on us the images of the internal body, which interact with the spectator's own movements in the cabin. In the experience provided by Hatoum, the sounds and images leave us speechless; using a specular device they express a pre-specular (pre-visual) experience. Consequently, it seems to me that the culture in which we are living today is continuously offering us a wealth of images to use as mirrors in which to see ourselves reflected. It is precisely this experience of discontent that Hatoum conveys through her installation. Instead of asserting the body as one's own, the images of the internal body reveal it as strange and absent; therefore they cannot function as ideal images. No identification is possible. The images of the internal body belong to the "fragmented body" which precedes the imaginary unity of the mirror stage. In adult life, a regression can occur to this fragmented body, in the form of an "aggressive disintegration of the individual," for example in cases of hysteria or more simply in the case of a physical illness.

According to Lacan, the images of the fragmented body remain outside the visual field; they are exoscopic. They remain outside the realm of the imaginary and outside the domain of the symbolic: they are not of the order of representation. Since Foreign Body offers us images of the "fragmented body," these endoscopic images are in fact exoscopic. The figuration of the internal body cannot be integrated into body image understood as a corporeal unity. The fragmented body manifests itself at a moment when the body image is shattered. What we see here is a visual presentation of what cannot be represented, what cannot be assimilated into body image: hence its strangeness. Hatoum's Foreign Body can therefore be seen as a figuration of what these images of the body potentially are.

\section{Illustrations}

The medical image can be considered as an experience of the image inseparable from its enunciation. It is an image at work, an imageact, a gesture of production joined to an act of reception and contemplation. In the work of 
Mona Hatoum, foreignness is at the heart of her artistic message, either as an impossibility of referring oneself to a unified body, or as a message of identity disintegration which signals an impossibility of identification.

Hatoum's work deals with experiences of displacement, of disorientation, of identity reconstruction, of the disorder that generates life and of the profound feeling of discontent that stems from it.

Since World War II and the popularization of $x$ ray scanning, a number of artists have used images of this kind. At first, it was to try and reflect on the inner and transparent world represented by medical imaging. This was the case for example with Francis Bacon, who in the 1950s used a radiological manual - Positioning in Radiology, written by Kathleen Clara Clark in 1934 - as a kind of handbook for the creation of some of his works, such as Head Surrounded by Sides of Beef (1954), where the artist uses x-ray images as references, in order to represent a living body in the shape of a carcass.

The diseased body is also grasped such as it is, for example in the work of another American artist, Laura Ferguson, the author of the series The Visible Skeleton. The artist began to experience physical deformation following an attack of acute scoliosis. At the age of 13, Ferguson underwent spine fusion surgery. The transformation of her body led her to experiment with new concepts of space and gravity, while also developing a new consciousness of certain bodily processes, such as breathing and movement. To create her pieces, Laura Ferguson initially used images from her own medical files; later she started working with files of others patients. According to the artist, the series tells the story of her own journey through illness and shows how she transformed the experience of her medicalized body into art.

Faced with the effect of the visual experience imposed on the body by these imaging techniques, the subject who is brought back to a pre-specular experience is necessarily gripped by anxiety. The artistic gesture can therefore be thought of as an act of trying to access the constituent experience of anxiety and of learning how to use it to reconstruct one's body. By incorporating and transforming the images produced by medical technology (X-rays, tomography, resonance), the artist creates a new vision of the body and redefines, among other things, the notion of the portrait, by questioning the signification of the unified image of the self.

To take another example, the Brazilian artist Monica Mansur explores the images produced by $x$-ray scanning, endoscopy, ultrasound and tomography, and makes them interact with cultural interpretations. Her work depicts medicalized scientific bodies in an artistic scenario. As Rosana Horio Monteiro argues in connection with Mansur's work, "the popularization of medical images in different media contexts (cinema, television, advertising) has afforded a large public access to a perspective previously reserved to the specialized eye of a single physician. It has also contributed to the creation of a culture dependent on images and the technologies that produce them. The methods of illuminating the body's interior and its transparency have increasingly become cultural products or artifacts." 5

In her work as a graphic designer, Monica Mansur regularly explores medical images. Since 1995, the year of her first exhibition of works produced from $x$-ray images and printed on adhesive tape and gauze, and until the most recent years, when she has been creating what she calls her "crystal landscapes" or rephotographic images, Mansur explores the creative potential inherent in reproduction techniques and reflects on the esthetics of repetition. Her re-photography works consist of re-photographed and printed images, which are based on a series of medical exams. The artist takes a photo of an image produced during an exam and then digitalizes and alters it. Using this method she removes certain parts, adds or reduces the light exposure and modifies the physical space. The image is then printed on different materials, such as adhesive tape and gauze. In 1996, Mansur learned how to use video technology and created an installation 
with mobile images of the interior of the human stomach and colon. The images used by Mansur may be of her own body or any other: they are non-identities. Collected at random, these images can sometimes belong to the deceased, the ill and the healthy. ${ }^{6}$

\section{Discussion 2}

In the works presented above, the questions of the body and of our identity lie at the heart of the artistic message, either as an impossibility of referring oneself to a unified body, or as a message of identity disintegration, signaling an impossibility of identification.

Moreover, the artist's message may also center on obscenity, testifying to the intrusion caused by these imaging methods. Cris Bierrenbach's Retratos intimos (2003) is a series of five digital blowups of $x$-ray images showing the interior of the body, from the stomach to the knees, together with five sharp or pointed objects (a syringe, a fork, scissors, a knife, a forceps), covered with Vaseline and inserted in the vagina.

The radiologist and artist Rodolphe von Gombergh has developed a method of medical imaging enabling the interior of the body to be examined with great precision, yet without the need to insert a camera into the organism. In the medical domain, these 3D images are valuable to both medical practitioners and patients, since they remove the need for anesthesia or hospitalization, while allowing us to travel through the deepest corners of the human body. In the domain of art, Von Gombergh's spectacular images invite us on a journey between reality and fiction. Thanks to a three-dimensional image of the body, a surgeon can operate on a patient remotely, using a robot, and with the utmost precision, by preserving the feeling of volume and the distances between organs. Von Gombergh believes that his 3-D images of lungs could also aid in detecting certain anomalies: a strange alliance between art and science, recalling the presentation of the artist's work Transparent
Women, who, thanks to their luminosity, are established as a fetish.

Ultimately, what we see is inseparable from and depends on our way of seeing. The key question of $\mathrm{my}$ research is articulated by the idea that given the questions of identity present in these kinds of specular ordeal, clinical work with patients who are confronted with these types of experiences, as with anyone else affected by the mediatization of medical icons, also revolves around the need to allow the subject to produce a gaze for himself, a gaze which has previously been confiscated by the techno-scientific discourse.

\section{Conclusion}

What we see depends on our way of seeing. The central question of my research is the idea that considering the issues of identity raised by these specular ordeals, the main stake of clinical work with the patients who undergo them, as with any modern subject in his relationship to medicine, is to allow the subject to fabricate a gaze, a gaze which has been appropriated by the technoscientific discourse itself. The clinician should follow the processes of transformation, not try to predict them. Today's technology produces significant modifications in our apprehension of the real and the world. This specificity must be questioned from the standpoints of both the normal and the pathological.

Leroi Ghouran has shown the role technological tools play in the process of hominization. Each historical era has its own kinds of progress, transforming the human being by making him dependent on precisely those prostheses that simultaneously open up new possibilities. This anthropological fact is confirmed by the psychoanalyst Harold Searle. In Non-human Environment, Searle points out that the nonhuman element of the human environment represents one of the most fundamental constituents of psychic life. For Searle, the ability or inability of the human being to have a constructive relationship with his non-human surroundings contributes to his psychical 
equilibrium or lack thereof. Therefore, technology is far from being psychologically neutral.

Faced with these body images, art invites us to free up -associative thought and examine their psychological and political dimensions. It questions these dimensions with respect to identity. Psychoanalysis enables us to identify and express the psychic stakes involved in this experience. Art's way of illustrating body representation resonates in the words we hear in our everyday clinical work, in hospitals, therapy groups and other areas of the mental health system, in all the places of discussion where different perspectives meet.

\section{Bibliography:}

Agamben, G. (2007). Qu'est-ce qu'un dispositif ? Paris : Éd. Payot \& Rivages.

Ferenczi, S. (1933). L'influence de Freud sur la médecine. Foucault, M. (2001). Dits et écrits, 1954-1988. Paris :

Gallimard.

Horio Monteiro, R. (2007). Images médicales entre art et science. Sociétés, 95.

Lacan, J. (1966). La place de la psychanalyse dans la médecine. Conférence. Le Bloc-Notes de la psychanalyse, 7 (9-40), Georg éditeur.

Lacan, J. (1966). Écrits. Paris : Seuil.

Lacan, J. (1992). Les Quatre concepts fondamentaux de la psychanalyse (1964). Le Séminaire, XI. Paris : Seuil.

Potier, R. (2007). L'imagerie médicale à l'épreuve du regard : enjeux éthiques de l'expérience face à l'image. Cliniques méditerranéennes: Psychanalyse et Psychopathologie Freudiennes. 76, 2007, 77-90.

Potier, R. (2009). L'image en médecine, esquisse et précipice. Recherches en Psychanalyse, 8|2009

Slatman, J. (2004). L'imagerie du corps interne. Penser le corps.

\section{Notes:}

${ }^{1}$ Transference: "Transference in psychoanalysis is essentially a displacement of emotional conduct related to an infantile object, especially the parents, onto another object or another person, especially the psychoanalyst in the course of the treatment." (Lagache, 1997, p. 33)

${ }^{2}$ The video is projected through a circular frame onto the floor of a cylindrical structure, which the spectator enters by one of two narrow doors situated on each side. The video footage is accompanied by a soundtrack of the sound of a heartbeat, as we can hear it from the different parts of the body examined by the camera. For about ten minutes, the camera quickly moves along the contours of the artist's body, mostly through a back-and-forth movement, entering its various orifices.

${ }^{3}$ Slatman, Jenny (2004). L'imagerie du corps interne. Penser le corps, 4.

${ }^{4}$ Ibid.

${ }^{5}$ Horio Monteiro, Rosana (2007/1). Images médicales entre art et science. Sociétés, $\mathrm{n}^{\circ} 95$.

${ }^{6}$ Rosana Horio Monteiro says the following about the artist's work: "Disindividualization of the contemporary subject is another element of the artist's work. It is the unnamed remnant of the medical examination." "The eye does not identify, the eye only says that this is a human body," argues Monica Mansur. "If this is a man or a woman, whether they are old or young, none of this can be decided without specialized medical knowledge; these medical visions exist only because they have been 'imagined' through a machine, whether it is a fiber optic video camera, a magnetic wave tunnel or laser beams which produce cross-sections of organs and bones," says Horio Monteiro, Ibid.

\section{The author:}

\section{Rémy Potier, PhD}

Clinical Psychologist, Practicing psychoanalyst. Associate Professor [Maître de Conférences], Psychopathology, Paris Diderot University at Sorbonne Paris Cité; Center for Research in Psychoanalysis, Medicine and Society Lab (EA 3522).

\section{Electronic reference:}

Rémy Potier, "Medical Imaging and Modern Art: Encounters over a Virtual Body", Research of Psychoanalysis [Online], 12|2011 published Dec. 22, 2011.

This article is a translation of Imagerie médicale et art contemporain, rencontres autour d'un corps virtuel 
Campus Paris Rive Gauche

Bâtiment Olympe de Gouges

11 , rue Jean Antoine de Baïf

75013 Paris

France

Translated by Kristina Valendinova (revised

translation).
Full text

\section{Copyright}

All rights reserved 